\title{
Cutaneous Radiation Injury
}

National Cancer Institute

\section{Source}

National Cancer Institute. Cutaneous Radiation Injury. NCI Thesaurus. Code C161515.

Radiation injury of the skin. 